\title{
Cost-of-illness studies in rare diseases: a scoping review
}

\author{
Lidia García-Pérez ${ }^{1,2,3,4,5^{*}}$ (10, Renata Linertová1,2,3,5, Cristina Valcárcel-Nazco 1,2,3,5, Manuel Posada ${ }^{6,7}$, \\ Inigo Gorostiza ${ }^{3,8}$ and Pedro Serrano-Aguilar ${ }^{1,3,5}$
}

\begin{abstract}
Objective: The aim of this scoping review was to overview the cost-of-illness studies conducted in rare diseases.

Methods: We searched papers published in English in PubMed from January 2007 to December 2018. We selected cost-of-illness studies on rare diseases defined as those with prevalence lower than 5 per 10,000 cases. Studies were selected by one researcher and verified by a second researcher. Methodological characteristics were extracted to develop a narrative synthesis.

Results: We included 63 cost-of-illness studies on 42 rare diseases conducted in 25 countries, and 9 systematic reviews. Most studies (94\%) adopted a prevalence-based estimation, where the predominant design was cross-sectional with a bottom-up approach. Only four studies adopted an incidence-based estimation. Most studies used questionnaires to patients or caregivers to collect resource utilisation data (67\%) although an important number of studies used databases or registries as a source of data (48\%). Costs of lost productivity, non-medical costs and informal care costs were included in $68 \%, 60 \%$ and $43 \%$ of studies, respectively.

Conclusion: This review found a paucity of cost-of-illness studies in rare diseases. However, the analysis shows that the cost-of-illness studies of rare diseases are feasible, although the main issue is the lack of primary and/or aggregated data that often prevents a reliable estimation of the economic burden.
\end{abstract}

Keywords: Cost-of-illness, Economic burden, Rare diseases, Scoping review

\section{Introduction}

Rare diseases (RD) are those that affect a small part of the population. A disease can be rare in one region and more prevalent in another, so there are different definitions and classifications. In Europe, the European Union Regulation on Orphan Medicinal Products (1999) defines a RD as a disease that affects not more than 1 person per 2000 in the population [1]. Although the number of patients with a specific RD is low, the sum of people affected by any RD is large. More than 6 thousand RDs have been

\footnotetext{
*Correspondence: lidia.garciaperez@sescs.es

${ }^{1}$ Servicio de Evaluación del Servicio Canario de la Salud (SESCS), Camino Candelaria No 44, $1^{\text {a }}$ planta, 38109 Canary Islands, El Rosario, Santa Cruz de Tenerife, Spain

Full list of author information is available at the end of the article
}

reported and it is estimated that they could affect about 29 million people in the European Union [2]. Similar to other health conditions, RDs impose a high social and economic burden for patients and their families, health care systems and society overall. Research in this field is key for progress in the knowledge of RDs in general [3] and for the sustainability of health care systems [4].

The economic burden of a disease is measured through cost-of-illness (COI) studies, and defined as the 'maximum amount that could potentially be saved or gained if a disease were to be eradicated' [5]. The estimation of this amount consists of three phases: identification, quantification and valuation in monetary terms of all resources associated with a disease. A COI study can be addressed by means of different designs and points of view. The perspective adopted to perform a COI study can be that of original author(s) and the source, provide a link to the Creative Commons licence, and indicate if changes were made. The images or other third party material in this article are included in the article's Creative Commons licence, unless indicated otherwise in a credit line to the material. If material is not included in the article's Creative Commons licence and your intended use is not permitted by statutory regulation or exceeds the permitted use, you will need to obtain permission directly from the copyright holder. To view a copy of this licence, visit http://creativecommons.org/licenses/by/4.0/. The Creative Commons Public Domain Dedication waiver (http://creativeco mmons.org/publicdomain/zero/1.0/) applies to the data made available in this article, unless otherwise stated in a credit line to the data. 
society, government, healthcare system, third party payer, employers or families. The type of perspective implies the inclusion of different types of costs which can be classified into three main categories: direct medical costs, direct non-medical costs and costs due to productivity losses (also called indirect costs).

COI studies can use either prevalence-based or incidence-based estimations and their design is usually a mathematical model or a cross-sectional study, either prospective or retrospective. Moreover, there are different approaches to quantify resources and calculate costs: a top-down approach, a bottom-up approach or a mixed approach. The selection of the characteristics of the COI study depends on the objective, disease and practical reasons, such as the available time and resources to conduct the study, as some designs are costlier than others.

COI studies enable comparison between countries and between diseases [6] so it is useful to learn about the relative burden of a RD in comparison to other RDs or nonrare diseases. Continuous or periodic monitoring of the COI would enable ascertaining the evolution of the burden for a country over time and, consequently, the effect of policies and new medical developments. In fact, COI studies can be a tool to prioritize diseases, their prevention and treatment, or to implement other non-healthcare policies, such as benefits for patients and families/ caregivers. In this regard, COI studies are one of the methods that meets the third goal of the International Rare Diseases Research Consortium (www.irdirc.org), that is, methods to assess the impact of diagnoses and therapies on RDs and, consequently, they must be part of the research agenda in the field of RDs.

Despite the relevance of this type of studies and the value of their results, a lack of COI studies focused on RDs is commonly acknowledged [7]. With the objective of depicting the state-of-the-art and the methodological characteristics of the COI in RDs, a scoping review of published literature was conducted and its results discussed following a systematic approach to research and report [8].

\section{Methods}

\section{Eligibility criteria}

We selected COI studies of RDs where the diseases had a reported prevalence lower than 5 per 10,000 cases according to the Orphanet database (www.orpha.net) or the most recent Orphanet's report [9], independently of the country where the research was conducted. To be consistent with the definition of COI, we included studies that at least estimated medical costs (even when the perspective was limited: only hospital perspective or only patient perspectives); consequently we excluded those studies that only estimated the cost of lost productivity. We also included systematic reviews of COI studies of RDs. We excluded case reports, conferences proceedings, and partial or complete economic evaluations of technologies; we also excluded studies on rare cancers, infectious diseases, comorbidities and/or adverse events.

\section{Information sources}

An initial search was conducted in April 2017; the definitive search was conducted in PubMed in January 2020 and included references published in English from January 2007 to December 2018. Editorials, letters and references without abstracts were excluded. Given the variety of RDs and the non-sensitiveness of the MeSH for RDs for our purpose, we conducted a search strategy where only cost-related terms were used, that is, without disease-related terms. To increase the specificity of our results, we searched for studies already indexed with the 'cost-of-illness' MeSH (see Table 1).

\section{Selection of sources of evidence, data charting process and synthesis of results}

One researcher (economist) screened the titles and abstracts. A second researcher (economist or physician) verified the selection, and disagreements were resolved by consensus. Characteristics of the selected studies were extracted, that is, country, disease or group of diseases, sample size, design, prevalence or incidence-based estimation, bottom-up or top-down approach, sources of patients and data, time horizon and discount, perspective and costs included, method for the estimation of productivity costs. Given the purpose of this review, we did not extract cost estimates nor did we assess the quality of the studies. We present a narrative synthesis.

\section{Results}

\section{Selection of sources of evidence}

The search identified 3222 references. After conducting an initial screening of titles and abstracts, 3107 were excluded. Given the non-specific search strategy, most excluded references during this phase focused on nonrare disease. Consequently, 115 full-text articles were

Table 1 Search strategy in PubMed

((((cost[Title] OR costs[Title] OR ((socioeconomic[Title] OR economic[Title]) AND burden[Title]) OR "cost of illness"[Title]))) AND ("cost of illness"[MeSH])) NOT (("editorial"[Publication Type] OR "letter"[Publication Type])) Filters: Abstract; Publication date from 2007/01/01 to 2018/12/31; Humans; English 
retrieved and assessed for eligibility. Forty four out of 115 references were excluded due to several reasons (see Fig. 1). The remaining 71 articles were selected for inclusion in this scoping review, 63 COI studies [10-72] and 9 systematic reviews [7, 30, 73-79] (one of the articles included a COI study and a systematic review [30]).

\section{Characteristics of sources of evidence and synthesis of results}

Table 2 shows the 63 included studies covering 42 RDs. Ten diseases were studied in more than one study (amyotrophic lateral sclerosis (ALS), haemophilia, Duchenne muscular dystrophy, cystic fibrosis, chronic inflammatory demyelinating polyradiculoneuropathy, idiopathic pulmonary fibrosis, juvenile idiopathic arthritis (JIA), Prader-Willi syndrome, systemic sclerosis, tuberous sclerosis complex); another 32 diseases were subject of only one study.

Table 3 shows the characteristics of the COI studies (see Additional file 1 for more detailed characteristics). The studies retrieved were conducted in 25 countries: USA (19) and Canada (4) in America; in Europe: Germany (14), Spain (14), The United Kingdom (14), Italy (12), Sweden (12), France (11), Hungary (8), Bulgaria (7), The Netherlands (2), and another 11countries with only

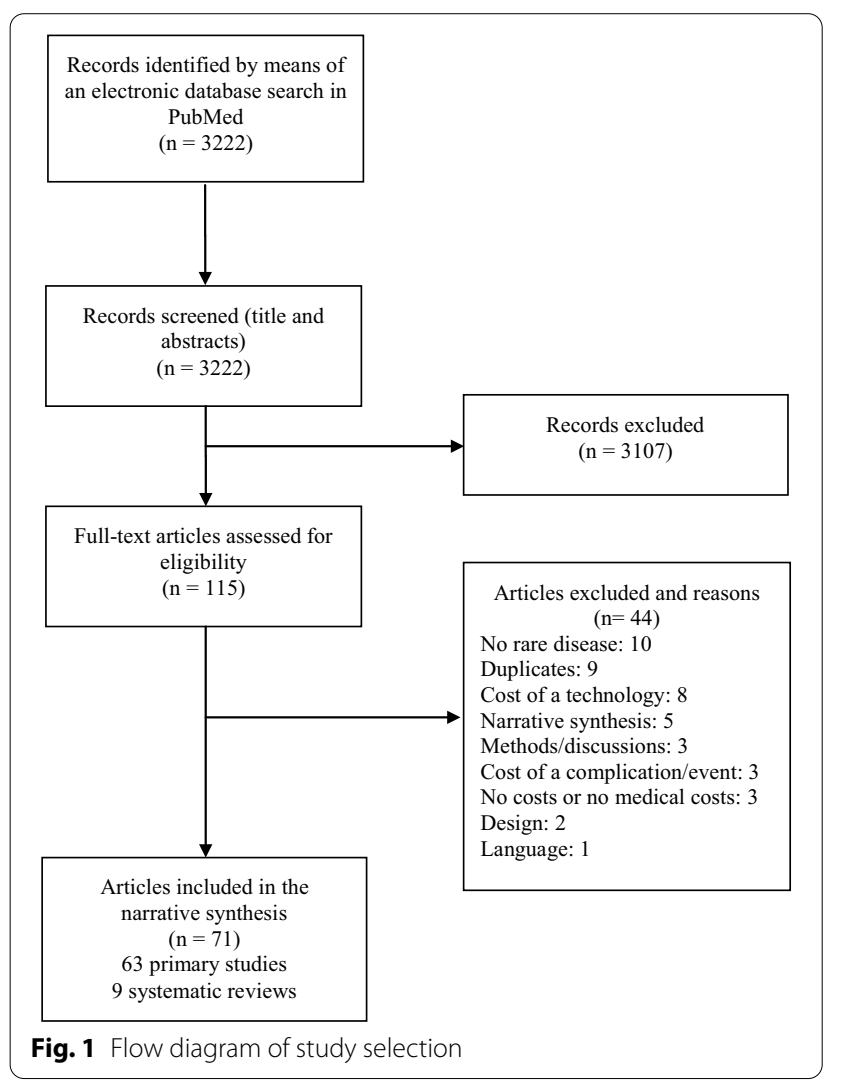

one paper (Belgium, Czech Republic, Denmark, Finland, Greece, Ireland, Norway, Poland); two studies were conducted in Australia and one in other 5 Asian countries: India, Iran, Korea, Taiwan and Turkey. The high number of studies in some European countries is due to the BURQOL-RD Study [80], which tackled the estimated burden of 10 RDs (cystic fibrosis, Duchenne muscular dystrophy, epidermolysis bullosa, fragile $\mathrm{X}$ syndrome, haemophilia, histiocytosis, JIA, mucopolysaccharidosis, Prader-Willi syndrome, and scleroderma) in Europe in 8 countries (Bulgaria, France, Germany, Hungary, Italy, Spain, Sweden, UK). Sample sizes ranged from as few as nine patients with multifocal motor neuropathy [42], 18 patients with Niemann-Pick disease type C [25] or 19 patients with lysosomal acid lipase deficiency [20], to larger samples, as 7855 patients with idiopathic pulmonary fibrosis [72], 7119 patients with sarcoidosis [52], or 6406 patients with pemphigus [23]. The studies with largest samples were conducted in the USA. Most diseases (78\%) had a prevalence of $1-9$ per 100,000 subjects.

Most studies $(\mathrm{N}=59 ; 94 \%)$ adopted a prevalencebased estimation, where the predominant design was a retrospective cross-sectional design (40 studies). Nine studies followed a cohort design where 4 reported costs for several periods $[20,32,36,57]$ and 5 collected data along a period of time but only reporting the average cost per year $[24,46,66,68,69]$. In another 7 cohort studies patients with the disease where compared with a control cohort of subjects without the disease $[13,23,29,52$, $56,61,72]$. A cost study nested in a clinical trial [47] and two mathematical models $[15,53]$ were also included. All prevalence-based studies, except the mathematical models, adopted a bottom-up approach.

Only four studies (6\%) adopted an incidence-based estimation approach with a patient's lifetime horizon; all four discounted future costs to estimate the current value of costs. One of them had a longitudinal design reporting monthly costs in patients with ALS [12]. The other three studies developed mathematical models to estimate the lifetime cost of cystic fibrosis [63], haemophilia [21] and Guillain-Barré syndrome [17]. The last two studies adopted a mixed approach using individual data from administrative databases and aggregated data from statistics and literature $[17,21]$. Both were able to populate the cost to estimate the national cost for the whole country. No studies using a pure top-down approach were identified.

The strategies to identify and access the patients were varied; eleven studies used more than one recruitment procedure. The studies recruited patients through patients' organisations (29\%), in hospitals and other centres $(38 \%)$, or through access to databases or patient registries $(51 \%)$. Some studies specifically recruited patients 
Table 2 Included cost-of-illness studies per disease

\begin{tabular}{|c|c|c|c|}
\hline Disease or group of diseases & Prevalence & $\begin{array}{l}\text { Number of } \\
\text { studies }\end{array}$ & References \\
\hline Amyotrophic lateral sclerosis (ALS) & $1-9 / 100,000$ & 8 & {$[11,12,19,24,34,41,48,62]$} \\
\hline Haemophilia & $1-9 / 100,000$ & 7 & {$[21,28,44,49,51,66,69]$} \\
\hline Duchenne muscular dystrophy & $1-9 / 100,000$ & 5 & {$[34,54,55,60,61]$} \\
\hline Cystic fibrosis & $1-9 / 100,000$ & 4 & {$[30,46,63,71]$} \\
\hline Chronic inflammatory demyelinating polyradiculoneuropathy & $1-9 / 100,000$ & 3 & {$[13,42,43]$} \\
\hline Idiopathic pulmonary fibrosis & $1-5 / 10,000$ & 2 & {$[68,72]$} \\
\hline Juvenile idiopathic arthritis (JIA) & $1-9 / 100,000$ & 2 & {$[31,45]$} \\
\hline Prader-Willi syndrome & $1-9 / 100,000$ & 2 & {$[37,56]$} \\
\hline Systemic sclerosis & $1-5 / 10,000$ & 2 & {$[22,38]$} \\
\hline Tuberous sclerosis complex & $1-5 / 10,000$ & 2 & {$[29,58]$} \\
\hline Achalasia (Idiopathic achalasia) & $1-9 / 100,000$ & 1 & {$[47]$} \\
\hline Acromegaly & $1-9 / 100,000$ & 1 & [35] \\
\hline Autosomal dominant polycystic kidney disease & $1-5 / 10,000$ & 1 & [16] \\
\hline Becker muscular dystrophy & $1-9 / 100,000$ & 1 & {$[54]$} \\
\hline Behçet's syndrome & $1-9 / 100,000$ & 1 & [59] \\
\hline Common variable immunodeficiency & $1-9 / 100,000$ & 1 & [53] \\
\hline Congenital hyperinsulinism & $1-9 / 100,000$ & 1 & [15] \\
\hline Cushing disease & $1-9 / 100,000$ & 1 & [33] \\
\hline Dermatomyositis & $1-9 / 100,000$ & 1 & {$[32]$} \\
\hline Dravet syndrome & $1-9 / 100,000$ & 1 & [64] \\
\hline Epidermolysis bullosa & $1-9 / 100,000$ & 1 & [10] \\
\hline Fragile $\times$ syndrome & $1-5 / 10,000$ & 1 & [70] \\
\hline Frontotemporal degeneration & $1-5 / 10,000$ & 1 & [18] \\
\hline Guillain-Barré syndrome & $1-9 / 100,000$ & 1 & [17] \\
\hline Hereditary angioedema & $1-9 / 100,000$ & 1 & [65] \\
\hline Histiocytosis & $1-9 / 100,000$ & 1 & [27] \\
\hline Lysosomal acid lipase deficiency, Cholesteryl ester storage disease type & $1-9 / 100,000$ & 1 & {$[20]$} \\
\hline Mucopolysaccharidosis & Depends on the type ${ }^{*}$ & 1 & [50] \\
\hline Multifocal motor neuropathy & $1-9 / 100,000$ & 1 & [42] \\
\hline Multiple system atrophy & $1-9 / 100,000$ & 1 & [67] \\
\hline Myotonic dystrophy & $1-9 / 100,000$ & 1 & [34] \\
\hline Narcolepsy-cataplexy syndrome & $1-5 / 10,000$ & 1 & [26] \\
\hline Niemann-Pick disease type $C$ & $1-9 / 100,000$ & 1 & [25] \\
\hline Paraproteinaemic demyelinating neuropathy & $1-9 / 100,000$ & 1 & [42] \\
\hline Pemphigus & Depends on the type ${ }^{* *}$ & 1 & [23] \\
\hline Phenylketonuria (PKU) & $1-5 / 10,000$ & 1 & [14] \\
\hline Primary childhood glaucoma and secondary childhood glaucoma & $1-9 / 100,000$ & 1 & [36] \\
\hline Progressive supranuclear palsy & $1-9 / 100,000$ & 1 & {$[67]$} \\
\hline Pulmonary arterial hypertension & $1-9 / 100,000$ & 1 & {$[57]$} \\
\hline Sarcoidosis & $1-5 / 10,000$ & 1 & {$[52]$} \\
\hline Spinal muscular atrophy & $1-9 / 100,000$ & 1 & [39] \\
\hline Spinocerebellar ataxias & $1-9 / 100,000$ & 1 & [40] \\
\hline
\end{tabular}

The sum is higher than 63 because 4 studies included more than one disease that fulfilled our inclusion criteria

* Type 1, Type 3, Type 6: 1-9/100,000; Type 2, Type 4: 1-5/10,000; Type 7: < 1 per million

** Superficial pemphigus: 1-9/100,000; pemphigus vulgaris: $1-5 / 10,000$ 
Table 3 Characteristics of the cost-of-illness studies included in the review

\begin{tabular}{|c|c|}
\hline Characteristic & Number of studies (\%) \\
\hline \multicolumn{2}{|l|}{ Prevalence or incidence-based estimation } \\
\hline Prevalence & $59(94 \%)$ \\
\hline Incidence & $4(6 \%)$ \\
\hline \multicolumn{2}{|l|}{ Design } \\
\hline Cross-sectional & $40(63 \%)$ \\
\hline Cohort & $10(16 \%)$ \\
\hline Cohort compared with a control cohort & $7(11 \%)$ \\
\hline Mathematical model & $5(8 \%)$ \\
\hline Cost study nested in a clinical trial & $1(2 \%)$ \\
\hline \multicolumn{2}{|l|}{ Prospective or retrospective } \\
\hline Retrospective & $55(87 \%)$ \\
\hline Prospective & $4(6 \%)$ \\
\hline \multicolumn{2}{|l|}{ Source of patients } \\
\hline Registries or databases & $32(51 \%)$ \\
\hline Hospital or other centres & $24(38 \%)$ \\
\hline Patients' organisations & $18(29 \%)$ \\
\hline \multicolumn{2}{|l|}{ Source of data } \\
\hline Questionnaires & $42(67 \%)$ \\
\hline Registries or databases & $30(48 \%)$ \\
\hline Other & $4(6 \%)$ \\
\hline \multicolumn{2}{|l|}{ Bottom-up or top-down approaches } \\
\hline Bottom-up & $59(94 \%)$ \\
\hline Top-down & $0(0 \%)$ \\
\hline Mixed & $4(6 \%)$ \\
\hline \multicolumn{2}{|l|}{ Time horizon } \\
\hline A year & $52(83 \%)$ \\
\hline Lifetime & $4(6 \%)$ \\
\hline Other & $11(17 \%)$ \\
\hline \multicolumn{2}{|l|}{ Perspective } \\
\hline Societal & $40(63 \%)$ \\
\hline Third payer/health system/government & $17(27 \%)$ \\
\hline Patients and families & $7(11 \%)$ \\
\hline Hospital & $3(5 \%)$ \\
\hline \multicolumn{2}{|l|}{ Costs included in the analysis } \\
\hline Medical costs & $63(100 \%)$ \\
\hline Non-medical costs & $38(60 \%)$ \\
\hline Lost productivity costs & $43(68 \%)$ \\
\hline Informal care costs & $27(43 \%)$ \\
\hline \multicolumn{2}{|c|}{ Method for the estimation of lost productivity costs } \\
\hline Human capital approach & $34(54 \%)$ \\
\hline Friction cost approach & $2(3 \%)$ \\
\hline Other & $8(13 \%)$ \\
\hline
\end{tabular}

in reference centres or special units related to the disease $[11,46,51,69]$ or used specific disease registries [22, 54]. But an important number of studies used large databases such as health insurance claims databases [33], MEDICARE [72], or primary health care databases such as the
Clinical Practice Research Datalink in the United Kingdom [29]. Other studies used social media associated to patients organizations to reach the patients [37, 50, 58].

Most studies collected resource utilisation data by means of questionnaires to patients or caregivers (67\%), and/or extracting data from medical charts or other type of databases, such as public or private insurance claim data, registries or databases (48\%). Questionnaires were self-reported by means of post, e-mail or online, or administered by telephone or face to face in a centre. As examples, questionnaires were designed ad hoc in some cases [25] or adapted from previous studies [42, 64]. They were usually administered once when patients were asked about resources utilisation during the last six months. Afterwards, these costs were doubled to estimate the annual costs incurred. Exceptionally, one study asked patients about the use of resources for the last three months, in two visits three months apart, so in the end the authors reported the cost of a six-month period [67]. Four studies collected data prospectively [47, $62,66,69]$. One study administered a monthly questionnaire during the first year and a biannual questionnaire during the second year [69]. Another study gave patients a diary to prospectively collect the data and avoid the recall bias of retrospective questionnaires [62]; this way of collecting data is usually more expensive than asking retrospectively only once. Those studies where the data was only extracted from medical charts or databases did not include out of pocket costs, non-medical costs and indirect costs. Most studies estimated the annual cost per person (83\%); the rest of studies reported costs using other time lengths such as one month, three months, half a year or several periods of years $(17 \%)$.

A total of 16 studies (25\%) attempted to estimate the costs for the overall population, generally assuming an approximate prevalence. Apart from the study by Lesen et al. that used a registry including all the population with acromegaly in Sweden [35] and the modelling studies [15, $17,21,53,63]$, three other studies strived to estimate the national cost of certain diseases. Larkindale et al. calculated the total national costs in the USA of ALS, Duchenne muscular dystrophy and myotonic dystrophy, by multiplying the total per-patient cost (medical, nonmedical and indirect costs) by the prevalence of each disease reported by the Orphanet report and the best USA studies [34]. ALS had the largest estimated national cost, followed by Duchenne muscular dystrophy and myotonic dystrophy [34]. Similarly, O'Hara et al. extrapolated the costs obtained from their samples with haemophilia to country population by using national prevalence weights for 5 European countries [49]. Finally, Hsu et al. used the National Health Insurance Research Database that covers 99\% of the population in Taiwan [24]. 
According to the costs included in the analysis, 63\% of studies adopted the perspective of the society and $27 \%$ the health care system perspective as a third payer (MEDICARE, insurance companies, government); $11 \%$ of studies adopted a very restricted perspective including only costs incurred by patients, such as out-of-pocket or informal care. Three studies reported more than one perspective [25, 48, 57]. Imrie et al., for example, performed two analyses from both the societal and healthcare system perspectives, combining different sources of data. They selected patients from national databases which did not include health care data, but this lack of health data was offset by questionnaires designed ad hoc for patients [25].

All studies included medical costs (as this was an inclusion criterion), $60 \%$ included non-medical costs, $68 \%$ included the cost of lost productivity, and $43 \%$ included costs of informal care. Some studies classified informal care as a cost of lost productivity of parents or caregivers.

The method to estimate the cost of lost productivity was the "human capital approach" (HCA) and the "friction cost approach" (FCA) in 54\% and 3\% of studies, respectively. Other studies used other methods such as estimating difference in income before and after the disease or using the statistical value of a human life (13\%). One study used two methods. Frenzen et al. used HCA for loss of productivity and the statistical value for premature deaths [17].

During the review we also identified eight systematic reviews on the costs of RDs: cystic fibrosis [30], Dravet syndrome [76], Duchenne muscular dystrophy [78], JIA [74], pulmonary arterial hypertension [75], systemic sclerosis [73], systemic vasculitis, i.e. Takayasu arteritis, Behçet's syndrome, and Wegener's granulomatosis [79], and the 10 diseases included in the BURQOL-RD project $[7,80]$.

\section{Discussion}

The objective of this review was to show the state-ofthe-art of the COI studies in the field of RDs. We found 63 papers that estimated the cost of 42 different RDs using several types of COI studies. Most studies were conducted in European countries, followed by the USA. Prevalence-based estimations are clearly preferred over incidence-based ones as it is usual with other type of diseases [5]. Nevertheless, we found four examples of incidence-based COI studies in our review, showing the feasibility of this approach for those diseases with sufficient information available for the relevant time horizon according to expected lifetime related to the disease.

Regarding the design, when we started this study in 2016, we only found one study where the cohort with the disease was compared with a group without the disease
[72]. Collard et al. used claims data from MEDICARE to compare healthcare costs before and after the diagnosis of idiopathic pulmonary fibrosis [72]. After updating the review we found another 6 studies, published between 2016 and 2018, with this kind of design. This design has advantages to estimate real incremental costs as it enables estimation of the difference on costs between having and not having the diseases [81]. There are no reasons to think that this design is not possible for RDs, as it has been performed for more prevalent diseases [82]. However, it can be hypothesised that for some RDs, where the disease rules over the patient's life, a huge part of health care resources could be directly related to the disease. Nonetheless, there are other methods to measure incremental costs, such as regression analysis or selection of those procedures or interventions directly related to the disease when collecting data from records or questionnaires [81].

Costs included in the analyses depend on the perspective or point of view of those using the information for making decisions, but the societal perspective is the most complete and the preferred among health economists $[81,83]$. Although the perspective was not always explicitly stated, the societal perspective was also the most common among the COI studies on RDs; the third-party payer perspective, that is, a health insurance or the public health care perspective, was also used in a quarter of the studies. Per protocol, all studies included direct medical costs. Regarding indirect costs, HCA was the most commonly used method in those studies that included them. No study followed the accepted recommendation for using both HCA and FCA to cope with the uncertainty associated with these costs [84]. It is worth to mention one study that was excluded from the review because it only included the cost of lost productivity of two RDs (systemic sclerosis, sarcoidosis) apart from one non-rare disease (systemic lupus erythematosus) [85].

Limited perspectives, such as the patient perspective, can be informative but underestimate the actual burden of the disease for society [86]. However, they can be useful to highlight the economic burden of a disease for families as Eijgelshoven et al. did when estimated the cost of phenylketonuria (PKU) for patients and caregivers in the Netherlands [14]. They found that $99 \%$ of out-of-pocket costs were because of expenditure on lowprotein food products, and that these costs were higher for severe PKU patients compared to mild PKU patients [14]; the actual economic burden of the disease for society as a whole is unknown. The perspective can have a dramatic influence on cost estimates depending on the health system, especially for those diseases which require caregivers dedication, those with high non-medical outof-pocket costs or for countries where certain therapies 
or services are not reimbursed by the public health care system or a third payer $[87,88]$. In those cases, the use of the perspective of society is especially critical. However, few studies report about the actual payers. For example, among the three most frequent diseases in our review (19 studies), only one study reported separately the cost paid by the patients and the cost paid by the government [48]. According to this study, the mean out-of-pocket costs per month related to ALS were $\$ 1871$ (US dollars, year 2013), that is, $67.2 \%$ of mean household income in South Korea [48].

A top-down approach is possible when aggregated data are available [82]. We were unable to find studies with a top-down approach, except for the models, possibly because of the lack of aggregated data in the field of RDs. That is why authors probably tried to estimate the cost of RDs collecting data from primary sources such as patients or clinical charts. Although the use of large administrative databases makes it difficult to isolate medical costs directly attributable to the disease [86], hampering the estimation of incremental costs, and despite the risk of recall bias, the use of the bottom-up approach through retrospectively collecting data from patients and/or reviewing clinical charts is increasing, both in prevalent diseases [74, 82, 86, 89-91] and in RDs as we have seen in this review. Moreover, the use of real world data to estimate costs could be reinforced with new methods of analysis and the access to massive health data. One example of the potentiality of this is the study by Cai et al. [92], study that was not included in our review because of the date of publishing, where it was possible to estimate the cost of 23 RDs within a covered population of 61 million by means of the health information exchange system in Shanghai.

Ideally, COI studies should report both per-patient cost estimates and national COI estimates [5, 82, 89]. On the one hand, the annual per-patient estimation is useful to report costs in detail and to elucidate cost drivers [82]. However, they are not useful to know the actual dimension of the economic burden. On the other hand, reliable national estimates are difficult without high quality data on disease prevalence and on the distribution of features such as severity in the population with the disease. In our review we have observed that some authors reported the estimation of the national COI cautiously, probably because of a lack of quality data on prevalence of RDs $[11,34,54,72]$.

Cost estimates for the same disease can vary between studies for several reasons, apart from differences between countries in terms of unit costs, reimbursement policies or clinical practice. For example, the place of recruitment of the patients (primary care, specialised care, population-based samples) might be a source of heterogeneity [93], i.e. samples are more or less severely ill, and consequently tending to be more or less costly [74, 86, 89]. Zhou et al. [69] selected patients with haemophilia A aged 2-64 years from racially and geographically diverse regions in the USA, but they had to be recruited in six federally supported haemophilia treatment centres, had to receive at least $90 \%$ of their haemophilia care at this type of centre, and had to meet specific clinical characteristics. Therefore, this sample could not be fully representative of the whole population with haemophilia A. The authors estimated the burden for the 222 recruited patients which represent, according to the authors, $1 \%$ of individuals with haemophilia receiving care at these specialised centres in the USA. In their words, specialised centres facilitate recruitment but limit representativeness of the sample [69]. However, this fact might be irrelevant in some RDs given the level of specialised care that some RDs require.

There are several ways of reaching the patients, recruitment through patient's organizations, by means of social media or accessing specific registries, databases or health centres [94]. Apparently, selecting patients from administrative databases could be more convenient than recruiting them from specialised centres in some circumstances [94]. But again, the drawback could be a potential selection bias. For example, those studies from the USA which use Medicare datasets, like many in our review, are estimating costs of patients aged 65 and above [82]. A community-based sample can facilitate the inclusion of a more representative group of patients, but the diagnosis of this cohort may depend on the reliability of the correct and complete codification of the diagnosis in the administrative data [94]. Moreover, theoretically the estimates should consider both the costs of undiagnosed patients [86] and diagnosed but untreated ones [89]. Otherwise there will be an underestimation of the actual economic burden [86]. If this occurs with common but poorly diagnosed chronic diseases such as depression or diabetes $[86,89]$, it is likely to be the case with RDs. In summary, the recruitment procedure and selection of the source of patients/data is critical to achieve a balance between representativeness and practicability.

Despite these issues, some authors can have a special interest in studying specific populations $[65,68]$ instead of mixed patients with the same disease, as is common to other diseases. Gidman et al. in their review identified papers which focused on specific subtypes of JIA or even patients treated with biological therapies [74]. This and other reviews found that biological therapies, new and expensive treatments, are associated with increased health care costs in more prevalent diseases like lupus, colorectal cancer and JIA [74, 82, 91]. Other cost drivers are ageing populations, as in atrial 
fibrillation [95], or productivity losses because of work capacity impairment, as in lupus [91]. All the above show the importance of studying the COI in RDs and non-rare diseases, their cost drivers, and evolution of the COI as well.

The methodology used to estimate the COI varies. In order to make comparison and interpretation possible, COI studies need to be more explicit about the scope, population characteristics, the costs included (perspective), how they were calculated, and so on $[74,80,82$, $84,86,89,91,93]$. For example, cost categories should be presented in detail, and direct and indirect costs should be reported separately to facilitate identification of cost drivers for specific diseases [82, 84, 89].

This scoping review has three main limitations. Firstly, the search was not exhaustive. It would impossible with the current technology to search and review all the cost studies conducted in RDs as there are millions of RDs. Secondly, the definition of RDs is based on prevalence and a specific reference source was used to decide if one disease is rare or not [9], but we are aware of the fact that there are geographical differences in prevalence of many RDs. Thirdly, we did not assess the methodological quality of the studies. However, given that the aim was to show an illustrative overview of this topic, we believe our approach was sufficiently efficient. Finally, it was not our aim to overview the methods behind COI studies and how to conduct them, as there are many other articles on this topic $[5,81,84,90,96]$, but to review a broad sample of COI studies in the field of RDs.

\section{Conclusions}

In summary, our review found a paucity of COI analysis in RDs, in line with previous reviews [7, 97]. Most COI studies used prevalence-based estimations, crosssectional design and bottom-up approaches, usually collecting data retrospectively and directly from patients or from clinical charts to estimate cost from the societal perspective. Apart from the common lack of data, COI studies of RDs are as feasible as COI studies of prevalent diseases. The main issue to address in the COI analysis of RDs is the lack of primary and/or aggregated data for most diseases that prevent a reliable estimation of the economic burden. Therefore, researchers have the mission of pursuing the generation of new knowledge where it does not exist, to comprehend the magnitude of the costs of RDs for society.

\section{Abbreviations}

ALS: Amyotrophic lateral sclerosis; COI: Cost-of-illness; FCA: Friction cost approach; HCA: Human capital approach; JIA: Juvenile idiopathic arthritis; PKU: Phenylketonuria; RD: Rare diseases.

\section{Supplementary Information}

The online version contains supplementary material available at https://doi. org/10.1186/s13023-021-01815-3.

Additional file 1. Main characteristics of the cost-of-illness studies included in the scoping review.

\section{Acknowledgements}

The authors would like to thank Esther Sanromá and some anonymous reviewers, and Jason Willis-Lee for copyediting support.

\section{Authors' contributions}

LGP and RL designed the review; LGP conducted the bibliographic search; $L G P, R L$, and CVN screened the references and extracted the data from the included studies; LGP and RL synthesized the results; MP, IG and PSA supervised the execution of the study and solved clinical points; LGP and RL were major contributors in writing the manuscript. All authors read and approved the final manuscript.

\section{Funding}

None.

Availability of data and materials

Not applicable.

\section{Declarations}

Ethics approval and consent to participate

Not applicable.

Consent for publication

Not applicable.

\section{Competing interests}

The authors declare that they have no competing interests.

\section{Author details}

${ }^{1}$ Servicio de Evaluación del Servicio Canario de la Salud (SESCS), Camino Candelaria No 44, 1 a planta, 38109 Canary Islands, El Rosario, Santa Cruz de Tenerife, Spain. ${ }^{2}$ Fundación Canaria Instituto de Investigación Sanitaria de Canarias (FIISC), Camino Candelaria No 44, 1 a planta, 38109 Canary Islands, El Rosario, Santa Cruz de Tenerife, Spain. ${ }^{3}$ Red de Investigación en Servicios de Salud en Enfermedades Crónicas (REDISSEC), Madrid, Spain. ${ }^{4}$ Instituto Universitario de Desarrollo Regional (IUDR), Universidad de La Laguna, Campus de Guajara, Camino de la Hornera, s/n, 38071 La Laguna, Santa Cruz de Tenerife, Spain. ${ }^{5}$ Centro de Investigaciones Biomédicas de Canarias (CIBICAN), Universidad de La Laguna, La Laguna, Spain. ${ }^{6}$ Institute of Rare Diseases Research, Institute of Health Carlos III, Monforte de Lemos, 5, 28029 Madrid, Spain. ${ }^{7}$ CIBER of Rare Diseases (CIBERER), Madrid, Spain. ${ }^{8}$ Osakidetza Basque Health Service, Basurto University Hospital, Avenida de Montevideo № 18, 48013 Bilbao, Spain.

Received: 31 July 2020 Accepted: 6 April 2021

Published online: 13 April 2021

\section{References}

1. European Parliament and Council. Regulation (EC) No 141/2000 of the European Parliament and of the Council of 16 December 1999 on orphan medicinal products. Off J Eur Communities [Internet]. 2000;I. 18/1(jenuary):1-5. https://ec.europa.eu/health/sites/health/files/files/eudralex/ vol-1/reg_2000_141_cons-2009-07/reg_2000_141_cons-2009-07_en.pdf.

2. Commission of the European Communities. Communication from the Commission to the European Parliament, the Council, the European Economic and Social Committee and the Committee of the Regions on Rare Diseases: Europe's challenges [Internet]. 2008. http://ec.europa.eu/ health/ph_threats/non_com/docs/rare_com_en.pdf. 
3. Julkowska D, Austin CP, Cutillo CM, Gancberg D, Hager C, Halftermeyer $J$, et al. The importance of international collaboration for rare diseases research: a European perspective. Gene Ther. 2017;24(9):562-71.

4. Graf von der Schulenburg JM, Frank M. Rare is frequent and frequent is costly: rare diseases as a challenge for health care systems. Eur J Heal Econ. 2015;16(2):113-8.

5. Segel JE. Cost-of-illness studies—A primer [Internet]. RTI International; 2006. p. 1-39. https://pdfs.semanticscholar.org/3bbf/0a03079715556ad 816a25ae9bf232b45f2e6.pdf.

6. Clabaugh G, Ward MM. Cost-of-illness studies in the United States: a systematic review of methodologies used for direct cost. Value Heal. 2008;11(1):13-21.

7. Angelis A, Tordrup D, Kanavos P. Socio-economic burden of rare diseases: a systematic review of cost of illness evidence. Health Policy. 2015;119(7):964-79. https://doi.org/10.1016/j.healthpol.2014.12.016.

8. Tricco AC, Lillie E, Zarin W, O'Brien KK, Colquhoun H, Levac D, et al. PRISMA Extension for Scoping Reviews (PRISMA-SCR): checklist and explanation. Ann Intern Med. 2018;169(7):467-73.

9. Orphanet. Prevalence and incidence of rare diseases [Internet]. Orphanet Report Series. 2018. http://www.orpha.net/orphacom/cahiers/docs/GB/ Prevalence_of_rare_diseases_by_alphabetical_list.pdf.

10. Angelis A, Kanavos P, Lopez-Bastida J, Linertova R, Oliva-Moreno J, Serrano-Aguilar $P$, et al. Social/economic costs and health-related quality of life in patients with epidermolysis bullosa in Europe. Eur J Health Econ. 2016;17(Suppl 1):31-42.

11. Athanasakis K, Kyriopoulos I-I, Sideris M, Rentzos M, Evdokimidis J, Kyriopoulos J. Investigating the economic burden of ALS in Greece: a cost-of-illness approach. Amyotroph Lateral Scler Front Degener. 2015;16(1-2):63-4. https://doi.org/10.3109/21678421.2014.932384.

12. Connolly S, Heslin C, Mays I, Corr B, Normand C, Hardiman O. Health and social care costs of managing amyotrophic lateral sclerosis (ALS): An Irish perspective. Amyotroph Lateral Scler Frontotemporal Degener. 2014:8421:1-5.

13. Divino V, Mallick R, DeKoven M, Krishnarajah G. The economic burden of CIDP in the United States: a case-control study. PLoS ONE. 2018;13(10):1-13.

14. Eijgelshoven I, Demirdas S, Smith TA, Van Loon JMT, Latour S, Bosch AM. The time consuming nature of phenylketonuria: a cross-sectional study investigating time burden and costs of phenylketonuria in the Netherlands. Mol Genet Metab. 2013;109(3):237-42. https://doi.org/10.1016/j. ymgme.2013.05.003.

15. Eljamel S, Griffiths A, Evans J, Banerjee I, Hussain K, Thompson R. The burden of congenital hyperinsulinism in the United Kingdom: a cost of illness study. Orphanet J Rare Dis. 2018;13(1):6-8.

16. Eriksson D, Karlsson L, Eklund O, Dieperink H, Honkanen E, Melin J, et al. Real-world costs of autosomal dominant polycystic kidney disease in the Nordics. BMC Health Serv Res. 2017:17(1):1-9.

17. Frenzen PD. Economic cost of Guillain-Barré syndrome in the United States. Neurology. 2008;71:21-7.

18. Galvin JE, Howard DH, Denny SS, Dickinson S, Tatton N. The social and economic burden of frontotemporal degeneration. Neurology. 2017:89(20):2049-56.

19. Gladman M, Dharamshi C, Zinman L. Economic burden of amyotrophic lateral sclerosis: a Canadian study of out-of-pocket expenses. Amyotroph Lateral Scler Front Degener. 2014;15(5-6):426-32.

20. Guest JF, Ingram A, Ayoub N, Hendriksz CJ, Murphy E, Rahman Y, et al. Healthcare resource use and costs of managing children and adults with lysosomal acid lipase deficiency at a tertiary referral centre in the United Kingdom. PLoS ONE. 2018;13(2):1-15.

21. Henrard S, Devleesschauwer B, Beutels P, Callens M, De Smet F, Hermans $C$, et al. The health and economic burden of haemophilia in Belgium: a rare, expensive and challenging disease. Orphanet J Rare Dis. 2014;9(1):39. https://doi.org/10.1186/1750-1172-9-39.

22. Bernatsky S, Hudson M, Panopalis P, Clarke AE, Pope J, LeClerca S, et al. The cost of systemic sclerosis. Arthritis Care Res. 2009;61(1):119-23.

23. Hsu D, Brieva J, Silverberg JI. Costs of care for hospitalization for pemphigus in the United States. JAMA Dermatol. 2016;152(6):645-54.

24. Hsu JC, Wu HC, Feng WC, Chou CH, Lai ECC, Lu CY. Disease and economic burden for rare diseases in Taiwan: a longitudinal study using Taiwan's National Health Insurance Research Database. PLoS ONE. 2018;13(9):1-14.
25. Imrie J, Galani C, Gairy K, Lock K, Hunsche E. Cost of illness associated with Niemann-Pick disease type C in the UK. J Med Econ. 2009;12(3):21929. https://doi.org/10.3111/13696990903245863.

26. Ingravallo F, Gnucci V, Pizza F, Vignatelli L, Govi A, Dormi A, et al. The burden of narcolepsy with cataplexy: how disease history and clinical features influence socio-economic outcomes. Sleep Med. 2012;13(10):1293300. https://doi.org/10.1016/j.sleep.2012.08.002

27. Iskrov G, Astigarraga I, Stefanov R, Lopez-Bastida J, Linertova R, OlivaMoreno J, et al. Social/economic costs and health-related quality of life in patients with histiocytosis in Europe. Eur J Health Econ. 2016;17(Suppl 1):67-78.

28. Jadhav U, Mukherjee K. Assessment of healthcare measures, healthcare resource use, and cost of care among severe hemophilia A patients in Mumbai region of India. J Postgrad Med. 2018;64(3):138-44.

29. Kingswood JC, Crawford P, Johnson SR, Sampson JR, Shepherd C, Demuth $\mathrm{D}$, et al. The economic burden of tuberous sclerosis complex in the UK: A retrospective cohort study in the Clinical Practice Research Datalink. J Med Econ. 2016:19(11):1087-98.

30. Kopciuch D, Zaprutko T, Paczkowska A, Nowakowska E. Costs of treatment of adult patients with cystic fibrosis in Poland and internationally. Public Health. 2017;148:49-55.

31. Kuhlmann A, Schmidt T, Treskova M, Lopez-Bastida J, Linertova R, OlivaMoreno J, et al. Social/economic costs and health-related quality of life in patients with juvenile idiopathic arthritis in Europe. Eur J Health Econ. 2016;17(Suppl 1):79-87.

32. Kwa MC, Ardalan K, Laumann AE, Silverberg Jl. Predictors of Hospitalization, Length of Stay, and Cost of Care Among Adults With Dermatomyositis in the United States. Arthritis Care Res. 2017;69(9):1391-9.

33. Broder M, Neary M, Chang E, Cherepanov D, Ludlam W. Burden of illness, annual healthcare utilization, and costs associated with commercially insured patients with cushing disease in the United States. Endocr Pract. 2015;21(1):77-86. https://doi.org/10.4158/EP14126.OR.

34. Larkindale J, Yang W, Hogan PF, Simon CJ, Zhang Y, Jain A, et al. Cost of illness for neuromuscular diseases in the United States. Muscle and Nerve. 2014:49(3):431-8.

35. Lesén E, Granfeldt D, Houchard A, Dinet J, Berthon A, Olsson DS, et al. Comorbidities, treatment patterns and cost-of-illness of acromegaly in Sweden: a register-linkage population-based study. Eur J Endocrinol. 2017;176(2):203-12.

36. Liu D, Huang L, Mukkamala L, Khouri AS. The economic burden of childhood glaucoma. J Glaucoma. 2016;25(10):790-7.

37. Lopez-Bastida J, Linertova R, Oliva-Moreno J, Posada-de-la-Paz M, Serrano-Aguilar P, Kanavos P, et al. Social/economic costs and healthrelated quality of life in patients with Prader-Willi syndrome in Europe. Eur J Health Econ. 2016;17(Suppl 1):99-108.

38. Lopez-Bastida J, Linertova R, Oliva-Moreno J, Serrano-Aguilar P, Posadade-la-Paz M, Kanavos P, et al. Social/economic costs and health-related quality of life in patients with scleroderma in Europe. Eur J Health Econ. 2016;17(Suppl 1):109-17.

39. López-Bastida J, Peña-Longobardo LM, Aranda-Reneo I, Tizzano E, Sefton $\mathrm{M}$, Oliva-Moreno J. Social/economic costs and health-related quality of life in patients with spinal muscular atrophy (SMA) in Spain. Orphanet J Rare Dis. 2017:12(1):1-7.

40. López-Bastida J, Perestelo-Pérez L, Montón-Álvarez F, Serrano-Aguilar P. Social economic costs and health-related quality of life in patients with degenerative cerebellar ataxia in Spain. Mov Disord. 2008;23(2):212-7.

41. López-Bastida J, Perestelo-Pérez L, Montón-Alvarez F, Serrano-Aguilar P, Alfonso-Sanchez JL, Montón-Álvarez F, et al. Social economic costs and health-related quality of life in patients with amyotrophic lateral sclerosis in Spain. Amyotroph Lateral Scler. 2009;10(4):237-43.

42. Mahdi-Rogers M, McCrone P, Hughes RAC. Economic costs and quality of life in chronic inflammatory neuropathies in southeast England. Eur J Neurol. 2014;21(1):34-9.

43. Mengel D, Fraune L, Sommer N, Stettner M, Reese JP, Dams J, et al. Costs of illness in chronic inflammatory demyelinating polyneuropathy in Germany. Muscle Nerve. 2018;58(5):681-7. https://doi.org/10.1002/mus. 26315.

44. Cavazza M, Kodra Y, Armeni P, De Santis M, Lopez-Bastida J, Linertova R, et al. Social/economic costs and quality of life in patients with haemophilia in Europe. Eur J Health Econ. 2016;17(Suppl 1):53-65. 
45. Minden K, Niewerth M, Listing J, Mobius D, Thon A, Ganser G, et al. The economic burden of juvenile idiopathic arthritis-results from the German paediatric rheumatologic database. Paediatr Rheumatol. 2009;27(5):863-9.

46. Mlčoch T, Klimeš J, Fila L, Vávrová V, Skalická V, Turnovec M, et al. Cost-ofillness analysis and regression modeling in cystic fibrosis: a retrospective prevalence-based study. Eur J Heal Econ. 2017;18(1):73-82.

47. Nenshi R, Takata J, Stegienko S, Jacob B, Kortan P, Deitel W, et al. The cost of achalasia: quantifying the effect of symptomatic disease on patient cost burden, treatment time, and work productivity. Surg Innov. 2010;17(4):291-4

48. Oh J, An JW, Oh SI, Oh KW, Kim JA, Lee JS, et al. Socioeconomic costs of amyotrophic lateral sclerosis according to staging system. Amyotroph Lateral Scler Front Degener. 2015;16(3-4):202-8.

49. O'Hara J, Hughes D, Camp C, Burke T, Carroll L, Diego DAG. The cost of severe haemophilia in Europe: the CHESS study. Orphanet J Rare Dis. 2017;12(1):1-8.

50. Pentek M, Gulacsi L, Brodszky V, Baji P, Boncz I, Pogany G, et al. Social/economic costs and health-related quality of life of mucopolysaccharidosis patients and their caregivers in Europe. Eur J Health Econ. 2016;17(Suppl 1):89-98.

51. Price VE, Hawes SA, Bouchard A, Vaughan A, Jarock C, Kuhle S. Unmeasured costs of haemophilia: the economic burden on families with children with haemophilia. Haemophilia. 2015;21(4):e294-9.

52. Rice JB, White A, Lopez A, Conway A, Wagh A, Nelson WW, et al. Economic burden of sarcoidosis in a commercially-insured population in the United States. J Med Econ. 2017;20(10):1048-55. https://doi.org/10.1080/13696 998.2017.1351371.

53. Sadeghi $B$, Abolhassani H, Naseri A, Rezaei N, Aghamohammadi ABS, et al. Economic burden of common variable immunodeficiency: annual cost of disease. Expert Rev Clin Immunol. 2015;11(5):681-8.

54. Schreiber-Katz O, Klug C, Thiele S, Schorling E, Zowe J, Reilich P, et al. Comparative cost of illness analysis and assessment of health care burden of Duchenne and Becker muscular dystrophies in Germany. Orphanet J Rare Dis. 2014;9(1):210.

55. Cavazza M, Kodra Y, Armeni P, De Santis M, López-Bastida J, Linertová $R$, et al. Social/economic costs and health-related quality of life in patients with Duchenne muscular dystrophy in Europe. Eur J Heal Econ. 2016;17(S1):19-29.

56. Shoffstall AJ, Gaebler JA, Kreher NC, Niecko T, Douglas D, Strong TV, et al. The high direct medical costs of Prader-Willi syndrome. J Pediatr. 2016;175:137-43. https://doi.org/10.1016/j.jpeds.2016.05.018.

57. Sikirica M, lorga SR, Bancroft T, Potash J. The economic burden of pulmonary arterial hypertension (PAH) in the US on payers and patients. BMC Health Serv Res. 2014;14(1):1-11

58. Skalicky AM, Rentz AM, Liu Z, Said Q, Nakagawa JA, Frost MD, et al. Economic burden, work, and school productivity in individuals with tuberous sclerosis and their families. J Med Econ. 2018;21(10):953-9. https://doi. org/10.1080/13696998.2018.1487447.

59. Sut N, Seyahi E, Yurdakul S, Senocak M, Yazici H. A cost analysis of Behcet's syndrome in Turkey. Rheumatology. 2007;46(4):678-82.

60. Teoh LJ, Geelhoed EA, Bayley K, Leonard H, Laing NG. Health care utilization and costs for children and adults with duchenne muscular dystrophy. Muscle Nerve. 2016;53(6):877-84.

61. Thayer S, Bell C, McDonald CM. The Direct cost of managing a rare disease: assessing medical and pharmacy costs associated with duchenne muscular dystrophy in the United States. J Manag Care Spec Pharm. 2017;23(6):633-41.

62. van der Steen I, van den Berg J-P, Buskens E, Lindeman E, van den Berg $\mathrm{LH}$. The costs of amyotrophic lateral sclerosis, according to type of care. Amyotroph Lateral Scler. 2009;10(1):27-34.

63. Van Gool K, Norman R, Delatycki MB, Hall J, Massie J. Understanding the costs of care for cystic fibrosis: an analysis by age and health state. Value Heal. 2013;16(2):345-55. https://doi.org/10.1016/j.jval.2012.12.003.

64. Whittington MD, Knupp KG, Vanderveen G, Kim C, Gammaitoni A, Campbell JD. The direct and indirect costs of Dravet Syndrome. Epilepsy Behav. 2018;80:109-13. https://doi.org/10.1016/j.yebeh.2017.12.034.

65. Wilson DA, Bork K, Shea EP, Rentz AM, Blaustein MB, Pullman WE. Economic costs associated with acute attacks and long-term management of hereditary angioedema. Ann Allergy Asthma Immunol. 2010;104(4):314-20. https://doi.org/10.1016/j.anai.2010.01.024.
66. Chen CX, Baker JR, Nichol MB. Economic burden of illness among persons with hemophilia B from HUGS Vb: examining the association of severity and treatment regimens with costs and annual bleed rates. Value Heal. 2017;20(8):1074-82. https://doi.org/10.1016/j.jval.2017.04.017.

67. Winter Y, Stamelou M, Cabanel N, Sixel-Döring F, Eggert K, Höglinger GU, et al. Cost-of-illness in multiple system atrophy and progressive supranuclear palsy. J Neurol. 2011;258(10):1827-34.

68. Yu YF, Wu N, Chuang C-C, Wang R, Pan X, Benjamin NN, et al. Patterns and economic burden of hospitalizations and exacerbations among patients diagnosed with idiopathic pulmonary fibrosis. J Manag Care Spec. 2016;22(4):414-23. https://doi.org/10.18553/jmcp.2016.22.4.414.

69. Zhou Z-Y, Koerper MA, Johnson KA, Riske B, Baker JR, Ullman M, et al. Burden of illness: direct and indirect costs among persons with hemophilia A in the United States. J Med Econ. 2015;18(6):457-65.

70. Chevreul K, Gandre C, Brigham KB, Lopez-Bastida J, Linertova R, OlivaMoreno J, et al. Social/economic costs and health-related quality of life in patients with fragile $X$ syndrome in Europe. Eur J Health Econ. 2016;17(Suppl 1):43-52.

71. Chevreul K, Michel M, Brigham KB, Lopez-Bastida J, Linertova R, OlivaMoreno J, et al. Social/economic costs and health-related quality of life in patients with cystic fibrosis in Europe. Eur J Health Econ. 2016;17(Suppl 1):7-18.

72. Collard HR, Chen S-Y, Yeh W-S, Li Q, Lee Y-C, Wang A, et al. Health care utilization and costs of idiopathic pulmonary fibrosis in U.S. medicare beneficiaries aged 65 years and older. Ann Am Thorac Soc. 2015;12(7):981-7. https://doi.org/10.1513/AnnalsATS.201412-5530C.

73. Fischer A, Zimovetz E, Ling C, Esser D, Schoof N. Humanistic and cost burden of systemic sclerosis: a review of the literature. Autoimmun Rev. 2017;16(11):1147-54. https://doi.org/10.1016/j.autrev.2017.09.010.

74. Gidman W, Meacock R, Symmons D. The humanistic and economic burden of juvenile idiopathic arthritis in the era of biologic medication. Curr Rheumatol Rep. 2015;17(5):31. https://doi.org/10.1007/ s11926-015-0508-1.

75. Gu S, Hu H, Dong H. Systematic review of the economic burden of pulmonary arterial hypertension. Pharmacoeconomics. 2016;34(6):533-50.

76. Jensen MP, Brunklaus A, Dorris L, Zuberi SM, Knupp KG, Galer BS, et al. The humanistic and economic burden of Dravet syndrome on caregivers and families: implications for future research. Epilepsy Behav. 2017;70:104-9. https://doi.org/10.1016/j.yebeh.2017.02.003.

77. Mukkada V, Falk GW, Eichinger CS, King D, Todorova L, Shaheen NJ. Health-related quality of life and costs associated with eosinophilic esophagitis: a systematic review. Clin Gastroenterol Hepatol. 2018;16(4):495-503.e8. https://doi.org/10.1016/j.cgh.2017.06.036

78. Ryder S, Leadley RM, Armstrong N, Westwood M, De Kock S, Butt T, et al. The burden, epidemiology, costs and treatment for Duchenne muscular dystrophy: an evidence review. Orphanet J Rare Dis. 2017;12(1):1-21.

79. Trieste L, Palla I, Baldini C, Talarico R, D’Angiolella L, Mosca M, et al. Systemic vasculitis: how little we know about their societal and economic burden. Clin Exp Rheumatol. 2012;30(4Suppl.73):6-8.

80. Lopez-Bastida J, Oliva-Moreno J, Linertova R, Serrano-Aguilar P. Social/ economic costs and health-related quality of life in patients with rare diseases in Europe. Vol. 17 Suppl 1, The European journal of health economics: HEPAC : health economics in prevention and care. Germany; 2016. p. 1-5.

81. Jo C. Cost-of-illness studies: concepts, scopes, and methods. Clin Mol Hepatol. 2014;20(4):327. https://doi.org/10.3350/cmh.2014.20.4.327.

82. Kriza C, Emmert M, Wahlster P, Niederländer C, Kolominsky-Rabas P. Cost of illness in colorectal cancer: an international review. Pharmacoeconomics. 2013;31(7):577-88.

83. Drummond MF, Sculpher M, Torrance G, O'Brien B, Stoddart G. Methods for the economic evaluation of health care programmes. 3rd ed. New York: Oxford University Press; 2005.

84. Larg A, Moss JR. Cost-of-illness studies: a guide to critical evaluation. Pharmacoeconomics. 2011;29(8):653-71.

85. Kawalec PP, Malinowski KP. The indirect costs of systemic autoimmune diseases, systemic lupus erythematosus, systemic sclerosis and sarcoidosis: A summary of 2012 real-life data from the Social Insurance Institution in Poland. Expert Rev Pharmacoeconomics Outcomes Res. 2015;15(4):667-73.

86. Ng CS, Lee JYC, Toh MPHS, Ko Y. Cost-of-illness studies of diabetes mellitus: a systematic review. Diabetes Res Clin Pract. 2014;105(2):151-63. 
87. Doran CM, Einfeld SL, Madden RH, Otim M, Horstead SK, Ellis LA, et al. How much does intellectual disability really cost? First estimates for Australia. J Intellect Dev Disabil. 2012;37(1):42-9.

88. Porterfield SL, DeRigne L. Medical home and out-of-pocket medical costs for children with special health care needs. Pediatrics. 2011;128(5):892-900.

89. Luppa M, Heinrich S, Angermeyer MC, König H-H, Riedel-Heller SG. Cost-of-illness studies of depression: a systematic review. J Affect Disord. 2007;98(1-2):29-43.

90. Tarricone R. Cost-of-illness analysis. What room in health economics? Health Policy. 2006;77(1):51-63.

91. Zhu TY, Tam LS, Li EK. Cost-of-illness studies in systemic lupus erythematosus: a systematic review. Arthritis Care Res. 2011;63(5):751-60.

92. Cai X, Yang H, Genchev GZ, Lu H, Yu G. Analysis of economic burden and its associated factors of twenty-three rare diseases in Shanghai. Orphanet J Rare Dis. 2019;14(1):1-10.

93. Yabroff KR, Warren JL, Banthin J, Schrag D, Mariotto A, Lawrence W, et al. Comparison of approaches for estimating prevalence costs of care for cancer patients: what is the impact of data source? Med Care. 2009:47(7Supp|1):S64-9.
94. Serrano-Aguilar P, Linertová R, Posada-de-la-Paz M, López-Bastida J, González-Hernández N, Taruscio D, et al. Recruitment procedures for descriptive socio-economic studies in rare diseases. The BURQOL-RD project. Expert Opin Orphan Drugs. 2015;3(7):759-65. https://doi.org/10. 1517/21678707.2015.1057499.

95. Wolowacz SE, Samuel M, Brennan VK, Jasso-Mosqueda JG, Van Gelder IC. The cost of illness of atrial fibrillation: a systematic review of the recent literature. Europace. 2011;13(10):1375-85.

96. Linertová R, García-Pérez L, Gorostiza I. Cost-of-illness in rare diseases. Adv Exp Med Biol. 2017;1031:283-97.

97. Kanavos P, Aardweg S Van Den, Angelis A. Socio-economic burden of rare diseases: methodological framework and empirical evidence. London; 2011.

\section{Publisher's Note}

Springer Nature remains neutral with regard to jurisdictional claims in published maps and institutional affiliations.
Ready to submit your research? Choose BMC and benefit from:

- fast, convenient online submission

- thorough peer review by experienced researchers in your field

- rapid publication on acceptance

- support for research data, including large and complex data types

- gold Open Access which fosters wider collaboration and increased citations

- maximum visibility for your research: over $100 \mathrm{M}$ website views per year

At $\mathrm{BMC}$, research is always in progress.

Learn more biomedcentral.com/submissions 